\title{
Treatment of two postoperative endophthalmitis cases due to Aspergillus flavus and Scopulariopsis spp. with local and systemic antifungal therapy
}

\author{
Sayime Aydin¹, Bulent Ertugrul*2, Berna Gultekin³, Guliz Uyar ${ }^{4}$ and \\ Erkin $\mathrm{Kir}^{5}$
}

\begin{abstract}
Address: ${ }^{1}$ The Hospital of Dumlupinar University, Department of Ophthalmology, Kutahya, Turkey, ${ }^{2}$ Adnan Menderes University Medical Faculty, Department of Infectious Diseases and Clinical Microbiology, Aydin, Turkey, ${ }^{3}$ Adnan Menderes University Medical Faculty, Department of Microbiology and Clinical Microbiology, Aydin, Turkey, ${ }^{4}$ Adnan Menderes University Medical Faculty, Department of Infectious Diseases and Clinical Microbiology, Aydin, Turkey and 5Adnan Menderes University Medical Faculty, Department of Ophthalmology, Aydin, Turkey

Email: Sayime Aydin - sayimeaydin@mynet.com; Bulent Ertugrul* - mbulentertugrul@yahoo.com; Berna Gultekin - berngul@yahoo.com; Guliz Uyar-gulizuyar@yahoo.com; Erkin Kir - erkinkir@yahoo.com

* Corresponding author
\end{abstract}

Published: 31 July 2007

BMC Infectious Diseases 2007, 7:87 doi:10.1 186/147/-2334-7-87

This article is available from: http://www.biomedcentral.com/I47/-2334/7/87

(C) 2007 Aydin et al; licensee BioMed Central Ltd.

This is an Open Access article distributed under the terms of the Creative Commons Attribution License (http://creativecommons.org/licenses/by/2.0), which permits unrestricted use, distribution, and reproduction in any medium, provided the original work is properly cited.
Received: 12 July 2006

Accepted: 31 July 2007

\begin{abstract}
Background: Endophthalmitis is the inflammatory response to invasion of the eye with bacteria or fungi. The incidence of endophthalmitis after cataract surgery varies between 0.072-0.13 percent. Treatment of endophthalmitis with fungal etiology is difficult.

Case Presentation: Case I: A 7I-year old male diabetic patient developed postoperative endophthalmitis due to Aspergillus flavus. The patient was treated with topical amphotericin B ophthalmic solution, intravenous (IV) liposomal amphotericin-B and caspofungin following vitrectomy.

Case 2: A 72-year old male cachectic patient developed postoperative endophthalmitis due to Scopulariopsis spp. The patient was treated with topical and IV voriconazole and caspofungin.

Conclusion: Aspergillus spp. are responsible of postoperative fungal endophthalmitis. Endophthalmitis caused by Scopulariopsis spp. is a very rare condition. The two cases were successfully treated with local and systemic antifungal therapy.
\end{abstract}

\section{Background}

Endophthalmitis is an intraocular infection caused by bacteria or fungi. Eventhough it is a rare condition, therapeutic options are limited and it affects the vision seriously. The incidence of endophthalmitis after cataract surgery varies between $0.072 \%-0.13 \%$ as reported in publications of the past 10 years [1]. In $83 \%$ of postoperative endophthalmitis cases, the infectious agents are bacteria, especially gram positive bacteria. However, few studies have been based on collected microbiology data regarding fungi. In these series the rate of fungal endophthalmitis varies between $8.6-18.6 \%[2,3]$. This aspect is also lacking in another large prospective series[4]. Candida albicans and Aspergillus spp. are the most frequently isolated organisms in fungal cases $[2,5]$. Treatment of endophthalmitis with fungal etiology is difficult. Systemically or intra-vitreally administered amphotericin- $B$ is the most commonly used drug in the treatment of fungal 
endophthalmitis. It has been reported that it can also be given in the anterior chamber [6]. In recent years, new anti-fungal agents such as caspofungin and voriconazole have been developed as an alternative to amphotericin-B, and successful results were reported [7-10].

The present article discusses the outcomes of two cases of endophthalmitis due to A. flavus and Scopulariopsis spp. following phacoemulsification and intraocular lens (IOL) implantation.

\section{Case Presentation \\ Case I}

A 71-years old male, diabetic patient underwent phacoemulsification and IOL implantation for right-sided senile cataract. He underwent an operation due to colon cancer 4 years before cataract surgery and received chemotherapy for one year. He had controlled diabetes without signs of diabetic end organ diseases at the time of cataract surgery. Visual acuity was 0.7 preoperatively and achieved 1.0 at postoperative $2^{\text {nd }}$ week. Topical steroid and antibiotic drops were prescribed postoperatively. Medication was continued for one month. At postoperative third month, patient presented visual acuity decrease and redness in the operated eye. Visual acuity was counting finger at one meter. Slit lamp biomicroscopic examination showed ciliary injection, anterior chamber reaction and cotton fiber appearance between the IOL and posterior capsule (Figure 1 ). This was not noticed in previous follow-ups. Therefore possibility of a foreign body such as cotton was excluded. The appearance was similar to mould hyphae. Endophthalmitis was suspected and anterior chamber fluid and vitreous examples were cultured preoperatively. Amphotericin-B $(5 \mu \mathrm{g} / 0.1 \mathrm{cc})$ and cefuroxime $(1 \mathrm{mg} / 0.1 \mathrm{cc})$ were administered into the anterior chamber while amphotericin-B $(10 \mu \mathrm{g} / 0,1 \mathrm{cc})$, amikacin $(0.4 \mathrm{mg} / 0.1 \mathrm{cc})$ and vancomycin $(1 \mathrm{mg} / 0.1 \mathrm{cc})$ were given intravitreally. Despite this treatment, biomicroscopic and clinical appearance continued to deteriorate and IOL and capsular remnants were removed with anterior vitrectomy. Anterior chamber fluid, and vitreous examples were cultured perioperatively, IOL was also cultured. Amphotericin-B (5 $\mu \mathrm{g} / 0.1$ cc) and cefuroxime $(1 \mathrm{mg} / 0.1 \mathrm{cc})$ were administered into the anterior chamber. Topical amphotericin B $(0.1 \mathrm{mg} / \mathrm{cc})$ ophthalmic solution and intravenous (IV) liposomal amphotericin-B (Ambisome $\left.{ }^{\varpi}\right) \quad(3 \mathrm{mg} / \mathrm{kg} /$ day $)$ were started. Aspergillus flavus was isolated from the cultures. Dense fibrinoid reaction developed around the pupil and in the vitreous during the follow-up period. Pars plana vitrectomy and silicon oil injection were performed. Intraocular triamcinolone $(0.4 \mathrm{mg} / 0.1 \mathrm{cc})$ and amphotericin-B ( $2.5 \mu \mathrm{g} / 0.1 \mathrm{cc})$ injection performed. In-vitro susceptibility with $\mathrm{E}$ test revealed that the pathogen's MIC for amphotericin-B was $4 \mu \mathrm{g} / \mathrm{ml}$. Consequently, IV caspofungin (Cansidas ${ }^{\circledR}$ ), with a loading dose of $70 \mathrm{mg}$ for one day fol- lowed by a maintenance dose of $50 \mathrm{mg} /$ day for the following days, was added to IV liposomal amphotericin-B. In the second week of the treatment, nephrotoxicity due to systemically used liposomal amphotericin-B occurred. Therefore the treatment was continued with caspofungin only. Following the 6-weeks treatment, corrected visual acuity was 0.5 (based on logMAR chart) and caspofungin treatment was terminated. No signs or symptoms of endophthalmitis were observed during the 6-months followup.

\section{Case 2}

A 72-year old male patient with phthisical right eye had phacoemulsification and IOL implantation for senile cataract of the left eye. The patient, weighing only $36 \mathrm{~kg}$, was cachectic secondary to eating problems (nausea and vomiting) due to gastrectomy operation. He underwent this operation five years ago. He had received oral supplementation (with high protein content) before the cataract surgery. Fundus examination showed "dry type" age related macular degeneration. Preoperative visual acuity was 0.1 (based on Snellen chart) and achieved 0.5 (based on Snellen chart) after an uneventful phacoemulsification surgery. Topical steroid and ciprofloxacin treatment was started postoperatively. These medications were gradually reduced over a period of one month and stopped. The patient was referred to us for uveitis at postoperative third month. He was suffered from decreased vision and pain. Topical steroid drops had been prescribed. Visual acuity limited to hand motion and biomicroscopic examination showed inflammatory reaction in the anterior chamber.

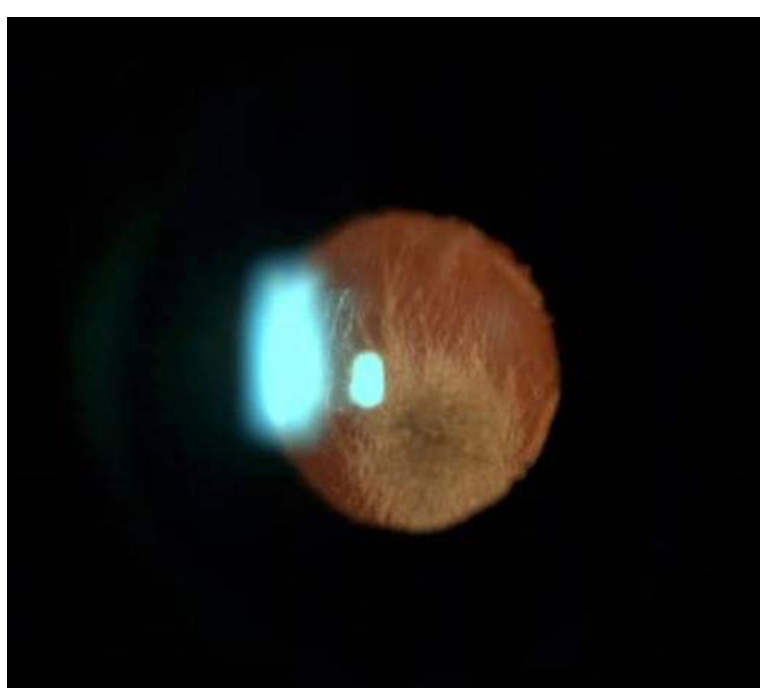

\section{Figure I}

The biomicroscopic image of endophthalmitis due to Aspergillus flavus in case I. 
There was a little improvement of the symptoms with steroid treatment. However, complaints were eventually intensified. Fibrinoid inflammatory reaction and membrane formation were noted around the pupil and the anterior chamber. Considering endophthalmitis, anterior chamber lavage was performed. Necrosis of and defect in iris were observed beneath the membrane. Samples of anterior chamber fluid were cultured. Vitreous was clean. Vancomycin (1 mg/0.1 cc) and amphotericin-B (5 $\mu \mathrm{g} / 0.1$ cc) were administered into the anterior chamber. The patient was treated empirically with topical fortified gentamicin and vancomycin ophthalmic solutions, oral ciprofloxacin (750 mg, b.i.d), intravenous (IV) vancomycin (500 mg, q.i.d) and meropenem (1 g, t.i.d). Due to suspicious fungal growth in culture, IV liposomal amphotericin-B ( $3 \mathrm{mg} / \mathrm{kg} /$ day) was started. Secondary to recurrence of dense fibrinoid inflammatory reaction, IOL extraction, vitrectomy and silicon oil injection were performed. Cornea was also edematous. Voriconazole $(2.5 \mu \mathrm{g} / 0.1 \mathrm{cc})$ was given into the silicon-filled vitreous space and amphotericin-B $(5 \mu \mathrm{g} / 0.1 \mathrm{cc})$ into the anterior chamber. Culture results yielded Scopulariopsis spp. In vitro susceptibility with $\mathrm{E}$ test revealed that the infecting organism had a MIC of $>32 \mu \mathrm{g} / \mathrm{ml}$ for amphotericin-B. MIC for voriconazole (VFEND ${ }^{\circledast}$-Pfizer) was found $8 \mu \mathrm{g} / \mathrm{ml}$ with susceptibility test using dilution method and MIC for caspofungin (Cancidas -MERCK SHARP \& DOHME) was $4 \mu \mathrm{g} / \mathrm{ml}$. Henceforth, IV amphotericin-B was stopped and IV voriconazole $(4 \mathrm{mg} / \mathrm{kg}$, b.i.d) and caspofungin $(50 \mathrm{mg} /$ day) were started. Voriconazole $(2.5 \mu \mathrm{g} / 0.1 \mathrm{cc})$ was injected into the silicon-filled vitreous space. Topical voriconazole $(0.01 \mathrm{mg} / \mathrm{cc})$ ophthalmic solution was started. As the hepatic enzymes elevated on the tenth day of the treatment, IV voriconazole was stopped and topical voriconazole and IV caspofungin were administered for a course of 8 -weeks. Visual acuity improved to counting finger from 3 meters at the postoperative $2^{\text {nd }}$ month. Fungal endophthalmitis did not recur during the 4 months follow-up period. Corneal edema was still present and visual acuity remained unchanged.

\section{Conclusion}

Endophthalmitis secondary to cataract surgery is a rare but serious condition that affects vision. Previous studies have shown that fungi are responsible of $8.6-18.6 \%$ of all culture positive postoperative endophthalmitis $[2,3]$. Endogenous fungal endophthalmitis usually occurs secondary to dissemination of organisms from a distant focus to the eye via blood and $2-15 \%$ of all endophthalmitis cases are estimated to occur in this way [11-13]. On the other hand, exogenous endophthalmitis occurs following eye surgery, penetrating traumas or corneal ulcerations. Even though both types are rare, diseases with abnormalities in immune system (diabetes, renal insufficiency, malignancies and AIDS), intravenous drug addic- tion, endocarditis, recent major surgery, organ transplantation, corticosteroid and cytotoxic drug use, prolonged antibiotic use, long term intravenous catheterization, genito-urinary and dental interventions increase the risk of endophthalmitis [12-15]. Postoperative fungal endophthalmitis is generally secondary to contaminated intraocular irrigation fluids, air conditioning systems and cluster infections during construction activities in hospitals [16-18].

Candida albicans and Aspergillus spp. are the most frequently isolated organisms in fungal endophthalmitis $[2,16,19,20]$. Candida spp. are isolated in the majority of endogenous endophthalmitis whereas Aspergillus spp. are responsible of postoperative fungal endophthalmitis $[3,5]$. Aspergillus endophthalmitis is usually caused by $A$. fumigatus and A. flavus [21,22]. With the exception of a single case, there is no information on endophthalmitis due to Scopulariopsis spp. in the literature [23].

Previous studies have shown that exogenous fungal endophthalmitis has a long latent period, lasting for weeks, even months after intraocular inoculation, and the mean latent period was 7 weeks among these cases [24]. In a study of Narang and colleagues [16] fungal endophthalmitis was noted even 90-210 days after the operation. First line of immunological defense against these fungi is the macrophages which engulf conidia. Hyphae are eliminated mainly by neutrophils. Disorders of neutrophil function play the major role in the development of infection by these pathogens in invasive aspergillosis models. Especially in diabetic patients, poor glycemic control is known to impair immune systems $[25,26]$. Same effect is observed after steroid; steroids facilitate the development of infection by impairing the defense mechanisms against the fungus exogenously acquired. We re-assessed our cases in the light of this information but failed to identify another endogenous focus following physical examination and analyses. The first case had type II diabetes that was not under control especially in the last months. The second case had excessive cachexia and biochemical analyses revealed excessive hypoproteinemia and hypoalbuminemia. Ophthalmic steroid solutions were used in both patients to suppress the local post operative inflammation. However, these solutions may impair the immune defense.

There are very few agents available for the treatment of fungal endophthalmitis. Moreover, inability to routinely test the sensitivity of the fungal pathogens under laboratory conditions presents a challenge in deciding on the treatment. Until recently, first choice in medical treatment of fungal endophthalmitis is systemic and intravitreal amphotericin-B [27-31]. However, development of resistance in fungal pathogens and concerns of focal retinal 
necrosis that might occur even with low doses of amphotericin-B have prompted new therapeutic alternatives to be developed. We are lacking sufficient clinical data on the efficacy of combination antifungal therapy. The results of in-vitro studies and animal models suggest that combination antifungal therapy may have additive activity against fungal infections. In some studies, combination of caspofungin and amphotericin- $\mathrm{B}$ was shown to have synergistic or additive against Aspergillus spp. and Fusarium spp. (marked decrease in MIC of both) [32]. As caspofungin inhibits fungal cell wall synthesis, penetration of amphotericin B through the cell membrane is facilitated. Combination antifungal therapy is an alternative approach in infections with multidrug resistant fungi and/ or infections that do not respond to standard therapy. [33]. In our first case, antifungal susceptibility test revealed a MIC of $4 \mu \mathrm{g} / \mathrm{ml}$ for amphotericin-B. Therefore caspofungin was added to the treatment. Acute renal failure developed on the second week of treatment which required termination of amphotericin-B. Treatment was continued with caspofungin to complete the 6-weeks course. In the second case, Scopulariopsis spp. was isolated with a serious resistance pattern. Scopulariopsis spp is known for its resistance to amphotericin-B. On the other hand, we are lacking sufficient data regarding intraocular penetration of caspofungin and its efficacy in ophthalmic infections. However, there are enough studies on voriconazole. Marangon and colleagues [8] carried out a study to determine in-vitro susceptibility of pathogens responsible of ocular fungal infections and showed that voriconazole was effective against most pathogens including mold and concluded that voriconazole could be used in ocular infections. In another study that investigated the reliability of intravitreal voriconazole, researchers showed that there was no retinal toxicity with doses $\leq 25 \mu \mathrm{g} / \mathrm{mL}$ in rats and argued that $100 \mu \mathrm{g}$ voriconazole can be used for human vitreous body of $4 \mathrm{ml}$ [7]. We administered amphotericin-B ( $3 \mathrm{mg} / \mathrm{kg} /$ day) IV and into the anterior chamber $(5 \mu \mathrm{g} / 0.1 \mathrm{cc})$ empirically. As soon as isolating Scopulariopsis spp. from the culture, antifungal susceptibility testing was carried out. As a result MICs for amphotericin-B, voriconazole and caspofungin were $>32 \mu \mathrm{g} / \mathrm{mL}, 8$ $\mu \mathrm{g} / \mathrm{mL}$ and $4 \mu \mathrm{g} / \mathrm{mL}$, respectively. Considering its high MIC value, $2.5 \mu \mathrm{g} / 0.1 \mathrm{cc}$ voriconazole was administered into the vitreous filled with silicon. Concurrently, amphotericin-B was replaced by IV voriconazole ( $4 \mathrm{mg} / \mathrm{kg}$, b.i.d) and caspofungin (Loading dose on day 1: $70 \mathrm{mg}$, Maintenance dose: $50 \mathrm{mg} /$ day). Following this treatment, clinical improvement was achieved in the patient. However, on day 10 of the treatment hepatic enzymes became elevated and this was accepted as toxic hepatitis. IV voriconazole was stopped and hepatic enzymes returned to normal during follow-up. Treatment was continued with IV caspofungin and locally administered voriconazole solution for 8 weeks.
There are few cases successfully treated with combination antifungal therapy in the literature $[9,10]$. Similarly, in our patients we used combination antifungal therapy. Unfortunately, one of our patient experienced side effects due to voriconazole and the other to amphotericin-B. Treatments were continued with caspofungin.

In conclusion, the success was not totally related to treatment with caspofungin. Local treatment with an antifungal agent and even a short course of another systemic antifungal also contributed to the good outcome. Both local and systemic antifungal therapy may be the best approach in endophthalmitis caused by resistant fungi.

\section{Competing interests}

The author(s) declare that they have no competing interests.

\section{Authors' contributions}

SA participated in the operation of both patients and helped to draft the manuscript. BE participated in manuscript design and coordination and involved in drafting the manuscript. He also prescribed the antifungal therapy of both patients. BG carried out the microbiologic studies and helped to draft the manuscript. GU followed the clinical improvement of both patients the hospitalization period. EK participated in the operation of both patients and helped to draft the manuscript. All of the authors have given final approval of the version to be published

\section{Acknowledgements}

The authors thank Department of Mycology, Ege University, School of Medicine for help in identification of Scopulariopsis spp.

Written consent was obtained from both patients.

\section{References}

I. Read RW: Endophthalmitis. In Ophthalmology 2nd edition. Edited by: Yanoff M. DJS. St Louis, Mosby Inc.; 2004: I I 52-I I 57.

2. Benz MS, Scott IU, Flynn HW Jr., Unonius N, Miller D: Endophthalmitis isolates and antibiotic sensitivities: a 6-year review of culture-proven cases. Am J Ophthalmol 2004, I 37:38-42.

3. Kunimoto DY, Das T, Sharma S, Jalali S, Majji AB, Gopinathan U, Athmanathan S, Rao TN: Microbiologic spectrum and susceptibility of isolates: part I. Postoperative endophthalmitis. Endophthalmitis Research Group. Am J Ophthalmol 1999, I 28:240-242.

4. Han DP, Wisniewski SR, Wilson LA, Barza M, Vine AK, Doft BH, Kelsey SF: Spectrum and susceptibilities of microbiologic isolates in the Endophthalmitis Vitrectomy Study. Am J Ophthalmol 1996, I22:1-17.

5. Anand AR, Therese KL, Madhavan HN: Spectrum of aetiological agents of postoperative endophthalmitis and antibiotic susceptibility of bacterial isolates. Indian J Ophthalmol 2000 , 48: $123-128$

6. Kuriakose T, Kothari M, Paul P, Jacob P, Thomas R: Intracameral amphotericin $B$ injection in the management of deep keratomycosis. Cornea 2002, 2 I:653-656.

7. Hua G, Pennesi M, Shah K, Qiao X, Hariprasad SM, Mieler WF, Wu SM, Holz ER: Safety of intravitreal voriconazole: electroretinographic and histopathologic studies. Trans Am Ophthalmol Soc 2003, I0 I: I83-9; discussion 189. 
8. Marangon FB, Miller D, Giaconi JA, Alfonso EC: In vitro investigation of voriconazole susceptibility for keratitis and endophthalmitis fungal pathogens. Am J Ophthalmol 2004, 137:820-825.

9. Durand ML, Kim IK, D'Amico DJ, Loewenstein JI, Tobin EH, Kieval SJ, Martin SS, Azar DT, Miller FS 3rd, Lujan BJ, Miller JW: Successful treatment of Fusarium endophthalmitis with voriconazole and Aspergillus endophthalmitis with voriconazole plus caspofungin. Am J Ophthalmol 2005, 140:552-554.

10. Breit SM, Hariprasad SM, Mieler WF, Shah GK, Mills MD, Grand MG: Management of endogenous fungal endophthalmitis with voriconazole and caspofungin. Am J Ophthalmol 2005, I39: 135-140.

II. Shrader SK, Band JD, Lauter CB, Murphy P: The clinical spectrum of endophthalmitis: incidence, predisposing factors, and features influencing outcome. I Infect Dis 1990, 162:1 I5- I20.

12. Kresloff MS, Castellarin AA, Zarbin MA: Endophthalmitis. Surv Ophthalmol 1998, 43:193-224.

13. Jackson TL, Eykyn SJ, Graham EM, Stanford MR: Endogenous bacterial endophthalmitis: a 17-year prospective series and review of 267 reported cases. Surv Ophthalmol 2003, 48:403-423.

14. Binder MI, Chua J, Kaiser PK, Procop GW, Isada CM: Endogenous endophthalmitis: an I8-year review of culture-positive cases at a tertiary care center. Medicine (Baltimore) 2003, 82:97-105.

15. Schiedler V, Scott IU, Flynn HW Jr., Davis JL, Benz MS, Miller D: Culture-proven endogenous endophthalmitis: clinical features and visual acuity outcomes. Am J Ophthalmol 2004, 137:725-73 I.

16. Narang S, Gupta A, Gupta V, Dogra MR, Ram J, Pandav SS, Chakrabarti $A$ : Fungal endophthalmitis following cataract surgery: clinical presentation, microbiological spectrum, and outcome. Am J Ophthalmol 200I, I 32:609-6I7.

17. Pettit TH, Olson RJ, Foos RY, Martin WJ: Fungal endophthalmitis following intraocular lens implantation. A surgical epidemic. Arch Ophthalmol 1980, 98:1025-1039.

18. Fridkin SK, Kremer FB, Bland LA, Padhye A, McNeil MM, Jarvis WR: Acremonium kiliense endophthalmitis that occurred after cataract extraction in an ambulatory surgical center and was traced to an environmental reservoir. Clin Infect Dis 1996 22:222-227.

19. Essman TF, Flynn HW Jr., Smiddy WE, Brod RD, Murray TG, Davis $\mathrm{JL}$, Rubsamen PE: Treatment outcomes in a $\mathbf{1 0}$-year study of endogenous fungal endophthalmitis. Ophthalmic Surg Lasers 1997, 28:185-194.

20. Elder MJ, Morlet N: Endophthalmitis. Clin Experiment Ophthalmol 2002, 30:394-398.

21. Riddell Iv J, McNeil SA, Johnson TM, Bradley SF, Kazanjian PH, Kauffman CA: Endogenous Aspergillus endophthalmitis: report of 3 cases and review of the literature. Medicine (Baltimore) 2002, 81:3II-320.

22. Tabbara KF, al Jabarti AL: Hospital construction-associated outbreak of ocular aspergillosis after cataract surgery. Ophthalmology 1998, 105:522-526.

23. Gariano RF, Kalina RE: Posttraumatic fungal endophthalmitis resulting from Scopulariopsis brevicaulis. Retina 1997, 17:256-258

24. Pflugfelder SC, Flynn HW Jr., Zwickey TA, Forster RK, Tsiligianni A, Culbertson WW, Mandelbaum S: Exogenous fungal endophthalmitis. Ophthalmology 1988, 95:19-30.

25. McMahon MM, Bistrian BR: Host defenses and susceptibility to infection in patients with diabetes mellitus. Infect Dis Clin North Am 1995, 9: I-9.

26. Leibovici L, Yehezkelli Y, Porter A, Regev A, Krauze I, Harell D: Influence of diabetes mellitus and glycaemic control on the characteristics and outcome of common infections. Diabet Med 1996, 13:457-463.

27. Eschete ML, King JW, West BC, Oberle A: Penicillium chrysogenum endophthalmitis. Mycopathologia I98I, 74:125-127.

28. Swan SK, Wagner RA, Myers JP, Cinelli AB: Mycotic endophthalmitis caused by Penicillium sp. after parenteral drug abuse. Am J Ophthalmol 1985, 100:408-410.

29. Lyratzopoulos G, Ellis M, Nerringer R, Denning DW: Invasive infection due to penicillium species other than P. marneffei. J Infect 2002, 45: I84-195.

30. Galland F, le Goff L, Conrath J, Ridings B: [Penicillium chrysogenum endophthalmitis: a case report]. J Fr Ophtalmol 2004, 27:264-266
31. Stevens DA, Kan VL, Judson MA, Morrison VA, Dummer S, Denning DW, Bennett JE, Walsh TJ, Patterson TF, Pankey GA: Practice guidelines for diseases caused by Aspergillus. Infectious Diseases Society of America. Clin Infect Dis 2000, 30:696-709.

32. Arikan S, Lozano-Chiu M, Paetznick V, Rex JH: In vitro synergy of caspofungin and amphotericin $B$ against Aspergillus and Fusarium spp. Antimicrob Agents Chemother 2002, 46:245-247.

33. Cuenca-Estrella M: Combinations of antifungal agents in therapy--what value are they? I Antimicrob Chemother 2004, 54:854-869.

\section{Pre-publication history}

The pre-publication history for this paper can be accessed here:

http://www.biomedcentral.com/1471-2334/7/87/prepub
Publish with Biomed Central and every scientist can read your work free of charge

"BioMed Central will be the most significant development for disseminating the results of biomedical research in our lifetime. "

Sir Paul Nurse, Cancer Research UK

Your research papers will be:

- available free of charge to the entire biomedical community

- peer reviewed and published immediately upon acceptance

- cited in PubMed and archived on PubMed Central

- yours - you keep the copyright
BioMedcentral 